\title{
MODELAMENTO TERMO-MECÂNICO DO AQUECIMENTO DE UMA PANELA DE AÇO USANDO O MÉTODO DA HOMOGENEIZAÇÃO PERIÓDICA LINEAR*
}

\author{
Lucas Breder Teixeira ${ }^{1}$ \\ João Pedro Chaib de Toledo Alves Pinto \\ Alain Gasser
}

\begin{abstract}
Resumo
Vasos metalúrgicos podem ser revestidos com linhas de tijolos refratários, com ou sem argamassa. Devido ao grande número de interfaces entre os tijolos, o subsistema tijolo/junta impõe dificuldades computacionais ao projeto da montagem. Buscando comparar a influência do projeto refratário nas tensões presentes na estrutura, um revestimento com juntas secas foi modelado utilizando um material homogêneo equivalente. As propriedades termo-mecânicas deste material equivalente foram determinadas usando o método de Homogeneização Periódica e dependem tanto da temperatura quanto do estado da junta (aberta ou fechada, nas duas direções). Este modelo foi usado para simular uma Panela de Aço através do Método dos Elementos Finitos (MEF) com o intuito de demonstrar a influência dos seguintes parâmetros: presença ou ausência de juntas; espessura da junta e projeto refratário. $O$ trabalho pretende auxiliar o desenvolvimento de projetos refratários e fornecer melhores estimativas da aplicabilidade de uma dada configuração.
\end{abstract}

Palavras-chave:Modelamento termo-mecânico; Revestimento refratário; Homogeneização Periódica; Panela de Aço.

\section{THERMO-MECHANICAL MODELING OF A STEEL LADLE HEATING USING THE PERIODIC LINEAR HOMOGENISATION TECHNIQUE}

\section{Abstract}

Metallurgical vessels can be lined with refractory bricks, with or without mortar. These refractory masonries may present different joint thicknesses. The bricks/joints subsystem imposes considerable computational problems to the masonry design due to the large amount of interfaces between them. To compare the influence of these designs on the maximum stresses in the structure, a masonry with dry joints was modeled by a homogeneous equivalent material that takes into account the possibility of joint closure. The thermo-mechanical properties of this equivalent material were determined using a periodic homogenization method. They are temperature depending and depend in the same time of the joint states (open or closed in the two directions). This masonry model was used to simulate the problem of a steel ladle with the finite element method. It demonstrates the influence of the following parameters: (a) presence or not of joints, (b) thickness of joints and(c) masonry design. This study brings a help for the design of refractory masonry linings and provides a better estimation of the applicability of a given lining.

Keywords: Thermomechanical modeling; Refractory masonry; Periodic Homogenization; Steel Ladle.

Engenheiro Mecânico, Magnesita Refratários S.A., Contagem, Minas Gerais, Brasil.

Engenheiro Mecânico, Magnesita Refratários S.A., Contagem, Minas Gerais, Brasil.

Professor, Universidade de Orléans, INSA-CVL, PRISME, Orléans, França. 


\section{INTRODUÇÃO}

Vários equipamentos da indústria de aço são revestidos com diferentes materiais refratários, com ou sem argamassa. As juntas entre os tijolos permitem uma expansão necessária para a obtenção de níveis de tensões que podem ser seguramente mantidos pelo refratário, cuja resistência mecânica é, normalmente, baixa. Portanto, para que seja possível o melhor entendimento do ciclo operacional do produto refratário é importante que essa redução de tensão seja levada em conta nos cálculos de engenharia, a fim de aumentar a precisão dos resultados.

Para determinar a influência dos diferentes projetos de montagens no perfil de tensão da estrutura refratária, é necessário a construção de um modelo, usando o método dos elementos finitos, de um equipamento sujeito a cargas termo-mecânicas que considere a presença das juntas. Pode-se alcançar este objetivo de duas maneiras possíveis: modelamento em meso-escala, que consiste em modelar cada tijolo e junta cada um com seu próprio comportamento, e o modelamento em macroescala que simula os tijolos e juntas através de um material homogêneo equivalente. O modelamento em meso-escala [1] demanda alto custo computacional para modelar, separadamente, os tijolos e as juntas. $\mathrm{Na}$ alternativa em macro-escala [2,3], a montagem é representada por um domínio contínuo equivalente. A grande maioria da literatura foca na homogeneização periódica de montagens refratárias usando Métodos dos Elementos Finitos (MEF) como proposto por Anthoine [4], por exemplo.

Neste estudo, as juntas e os tijolos são considerados materiais puramente elásticos. A homogeneização periódica permite o cálculo do comportamento equivalente da montagem. No caso de juntas sem argamassas (também chamadas de juntas secas), os possíveis estados de juntas são: abertas ou fechadas. Então, a equação constitutiva do material equivalente é linear elástica porém com diferentes constantes devido aos diferentes estados de juntas, como no trabalho de Luciano e Sacco [5]. O modelo em macro-escala usado neste trabalho é apresentado em Nguyen et al. [6] e brevemente discutido nas seções seguintes.

O modelo é usado, então, para simular o comportamento de uma Panela de Aço sujeita a uma curva de pré-aquecimento. Diferentes espessuras de juntas, do material equivalente, foram simuladas comparando os diferentes perfis de tensões do material refratário e da carcaça.

\section{MATERIAIS E MÉTODOS}

\subsection{Material homogêneo equivalente}

\subsubsection{Estado das juntas da montagem}

Neste modelo, dois tipo de juntas são distinguidas devido as suas orientações (junta horizontal e junta vertical) e, consequentemente, quatro estados de junta podem ser identificadas em um plano 2D como mostrado a seguir (nenhuma junta é considerada na terceira direção):

- As juntas estão abertas em ambas direções: a estrutura é totalmente discreta, estado 1 (Figura 1a);

- As juntas verticais estão fechadas e as horizontais estão abertas: a estrutura é uma matriz de faixas separadas, estado 2 (Figura 1b); 
- As juntas verticais estão abertas e as horizontais estão fechadas: a estrutura é um domínio contendo aberturas distribuídas, estado 3 (Figura 1c);

- As juntas estão fechas nas duas direções: a estrutura é completamente homogênea, estado 4 (Figura 1d).

Cada estado corresponde a uma diferente montagem periódica e, consequentemente, um diferente comportamento homogêneo equivalente.

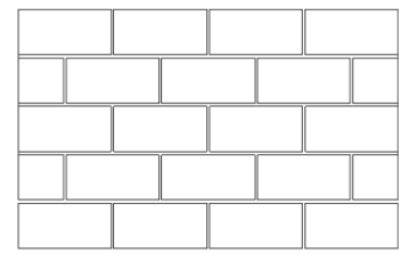

(a)

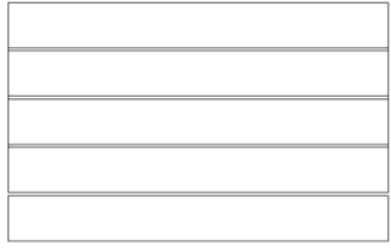

(b) $\rightarrow 1$

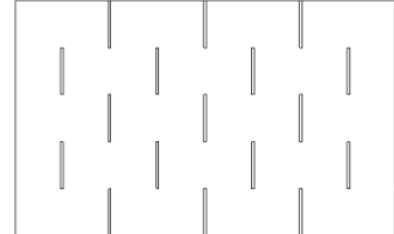

(c)

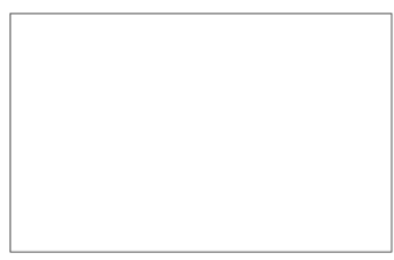

(d)

Figura 1. Estados das juntas: (a) estado 1, (b) estado 2, (c) estado 3, (d) estado 4.

\subsubsection{Comportamento da montagem homogênea equivalente}

Como a distribuição das juntas é diferente nas 3 direções, o material homogêneo equivalente da montagem é assumido como ortotrópico, ou seja, possui propriedades termo-mecânicas diferentes nas direções radial, axial e circunferencial da panela. Além disso, o comportamento das juntas e tijolos é considerado elástico resultando em 9 parâmetros elásticos para o material equivalente, para cada estado de junta: três módulos elásticos $\left(E_{1}, E_{2}, E_{3}\right)$, três coeficientes de Poisson $\left(v_{12}, v_{13}\right.$, $\left.v_{23}\right)$ e três módulos de cisalhamento $\left(G_{12}, G_{23}, G_{13}\right)$. Os parâmetros são determinados para os estados 1, 2 e 4 (através das relações mostradas na Tabela 1 e explicadas a seguir): Figura 1).

- Estado 1: todas as juntas estão abertas, não existe rigidez no plano 12 (vide

- Estado 4: todas as juntas estão fechadas, comportamento elástico do tijolo;

- Estado 2: juntas verticais estão fechadas e juntas horizontais abertas, não existe rigidez na direção 2 e a rigidez na direção 1 é a rigidez dos tijolos (Figura 1b).

Portanto, somente o estado 3 exige o uso da técnica de homogeneização.

Tabela 1. Parâmetros elásticos ortotrópicos do material homogêneo equivalente.

\begin{tabular}{cccccccccc} 
& $\mathrm{E}_{1}$ & $\mathrm{E}_{2}$ & $\mathrm{E}_{3}$ & $v_{12}$ & $v_{13}$ & $v_{23}$ & $\mathrm{G}_{12}$ & $\mathrm{G}_{13}$ & $\mathrm{G}_{23}$ \\
\hline Estado 1 & 0 & 0 & $\mathrm{E}_{\mathrm{b}}$ & 0 & 0 & 0 & 0 & $\mathrm{G}_{\mathrm{b}}$ & $\mathrm{G}_{\mathrm{b}}$ \\
\hline Estado 2 & $\mathrm{E}_{\mathrm{b}}$ & 0 & $\mathrm{E}_{\mathrm{b}}$ & 0 & $v_{\mathrm{b}}$ & 0 & 0 & $\mathrm{G}_{\mathrm{b}}$ & $\mathrm{G}_{\mathrm{b}}$ \\
\hline Estado 4 & $\mathrm{E}_{\mathrm{b}}$ & $\mathrm{E}_{\mathrm{b}}$ & $\mathrm{E}_{\mathrm{b}}$ & $v_{\mathrm{b}}$ & $v_{\mathrm{b}}$ & $v_{\mathrm{b}}$ & $\mathrm{G}_{\mathrm{b}}$ & $\mathrm{G}_{\mathrm{b}}$ & $\mathrm{G}_{\mathrm{b}}$
\end{tabular}

$E_{b}, v_{b}, G_{b}$ são as propriedades elásticas isotrópicas do tijolo. 
Como a montagem é periódica (Figura 2), a Homogeneização Periódica Linear $(\mathrm{HPL})$, combinado com uma abordagem baseada na energia de deformação, é bem adaptada para o estado 3. Para avaliar os parâmetros para este estado, a densidade de energia de deformação é computada através de um software de elementos finitos em um domínio de cálculo previamente determinado, para nove diferentes cargas (três tensões, três tensões biaxiais e três cargas de cisalhamentos). As energias de deformações obtidas são comparadas com a densidade de energia de deformação do material equivalente submetido à mesma carga e, assim, obtêm-se os nove parâmetros do material ortotrópico equivalente. Condições de contorno, que devem ser aplicadas no domínio de cálculo (um quarto da célula periódica, devido a 2 planos de simetria, Figura 2), são definidas a fim de respeitar a simetria e as condições periódicas [6]. A Figura 3 apresenta um exemplo de carga de tensão aplicada na direção 1 , onde $\boldsymbol{u}_{\boldsymbol{n}}$ é o deslocamento na direção $\boldsymbol{n}$ e $\boldsymbol{\beta}$ é um fator multiplicativo que reduz o deslocamento aplicado, mantendo a simulação no domínio das pequenas deformações. A condutividade e expansão térmica do material homogeneizado são assumidas como sendo iguais às do tijolo.

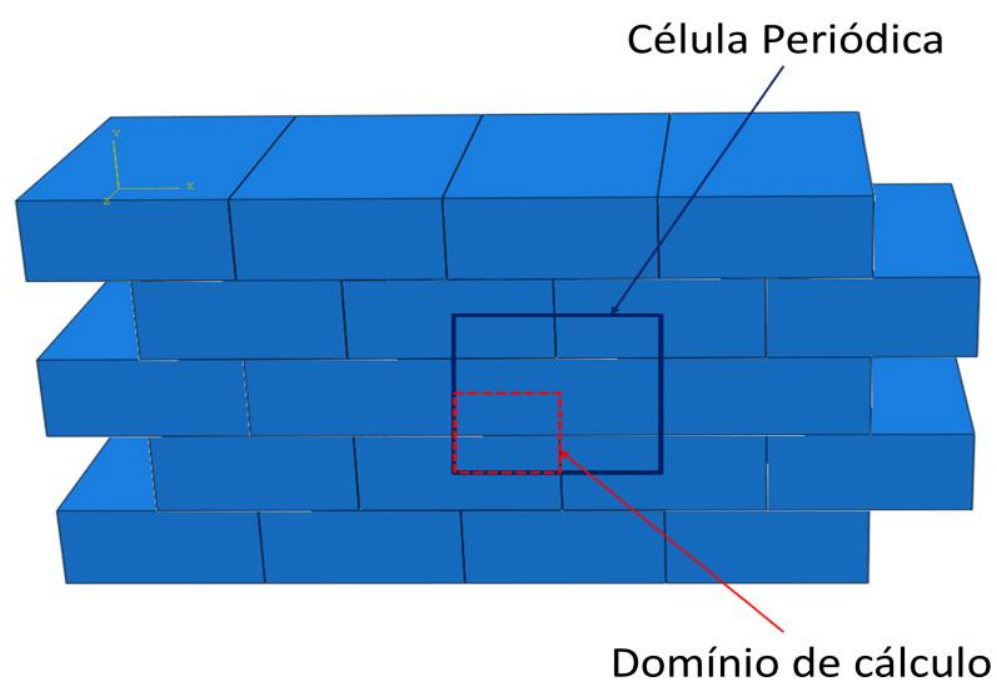

Figura 2. montagem plana, célula periódica (linha sólida) e domínio de cálculo (linha pontilhada).

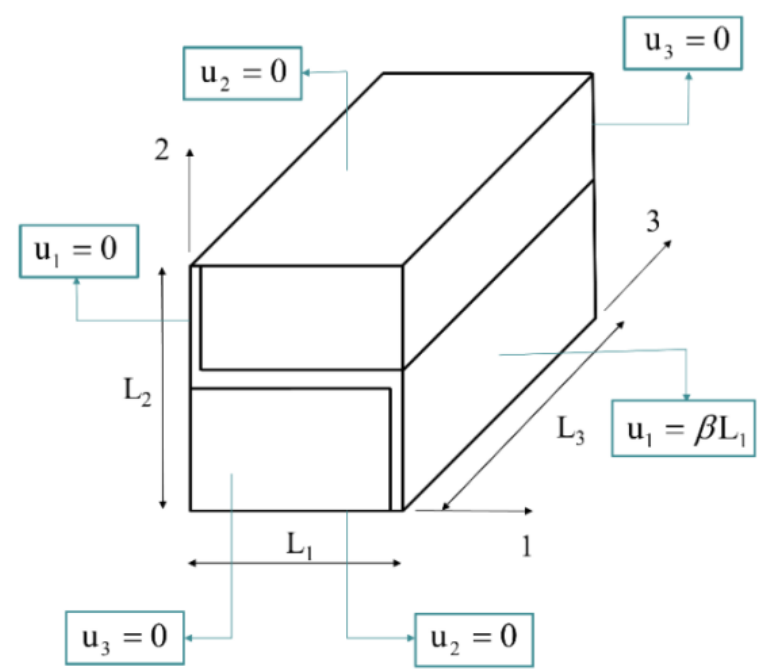

Figura 3. Domínio de cálculo submetido a uma carga na direção 1 e às outras condições de contorno. 


\subsubsection{Critério de fechamento de junta}

Como previamente dito, para cada estado de junta o material homogeneizado apresenta comportamento equivalente diferente. Para determinar em qual estado de junta, a montagem refratária se encontra, é necessário ter um critério que nos informará se a junta esta fechada ou aberta. Existem duas razões principais para o fechamento de junta: a deformação e o escorregamento dos tijolos (Figura 4).

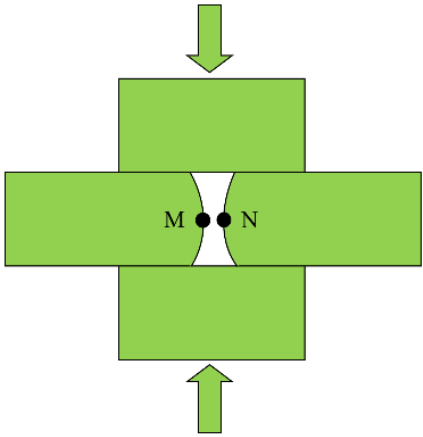

(a)

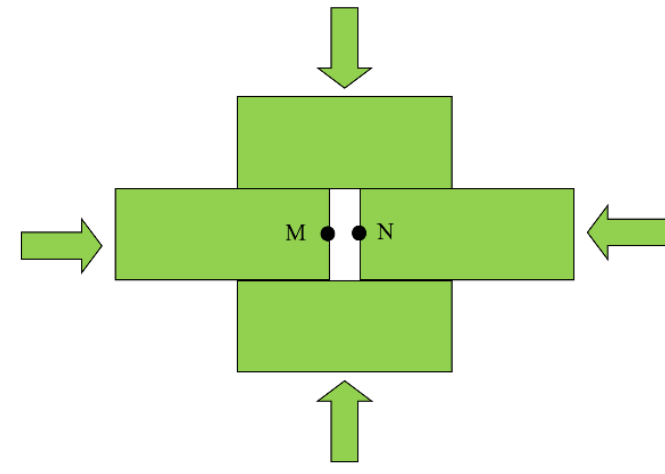

(b)

Figura 4. Critério de fechamento de junta. (a) deformação transversal do tijolo (efeito de Poisson). (b) Deformação normal e escorregamento dos tijolos.

O primeiro critério de fechamento das juntas é baseado na espessura inicial da junta entre as superfícies dos tijolos. Este critério compara a deformação do tijolo, devido ao efeito de Poisson, com o a espessura da junta. Caso a deformação seja maior, ocorre a mudança de estado da junta. [6].

O segundo critério, que leva em consideração a possibilidade de escorregamento do tijolo, é baseado na lei de atrito de Coulomb (Equação 1).

$$
\left|P_{t}\right|>f_{s}\left|P_{n}\right|(1)
$$

Se a força tangencial $P_{t}$ for maior que a força normal $P_{n}$ multiplicado pelo coeficiente de atrito $f_{s}$, o movimento relativo entre as superfícies ocorre e a junta se fecha, também caracterizando a mudança de estado da junta.

Os parâmetros dos critérios são determinados usando as mesmas simulações usadas na identificação dos parâmetros mecânicos do material.

O critério de escorregamento é usado somente no estado 3 porque nenhum tipo de escorregamento acontece nos outros estados.

\subsection{Modelamento da Panela de Aço}

A Panela modelada neste estudo contém um revestimento refratário com uma camada de trabalho, uma camada backfill e duas camadas permanentes. Uma massa, com propriedades de material aproximadas às dos materiais vizinhos, foi usada para preencher lacunas entre o revestimento permanente e a chapa do fundo e entre o revestimento de trabalho e a chapa de borda da Panela de Aço. Todos os materiais refratários do revestimento de trabalho (montagem com juntas secas) foram homogeneizadas usando a técnica HPL. As outras camadas foram consideradas blocos monolíticos. O tamanho do tijolo, do revestimento de trabalho, é $160 \times 100 \mathrm{~mm}$ na face quente, variando na dimensão da espessura. A Figura 5 
apresenta as dimensões, em milímetros, de cada camada presente na Panela de aço.

É considerado que a panela é sustentada pelos munhões. Além disso, para economizar tempo e recurso computacional, apenas um quarto da panela foi simulada, devido aos dois planos de simetria, e a carcaça foi modelada usando elementos de cascas. A espessura da parede da carcaça foi modelada com espessura de $25 \mathrm{~mm}$ e o fundo com $30 \mathrm{~mm}$. Os refratários e os munhões foram modelados usando elementos sólidos. Como a homogeneização já induz uma nãolinearidade considerável no modelo, contatos não-lineares foram usados apenas na linha de trabalho, entre o revestimento da parede e o revestimento do fundo, com um coeficiente de atrito igual a 0,2.

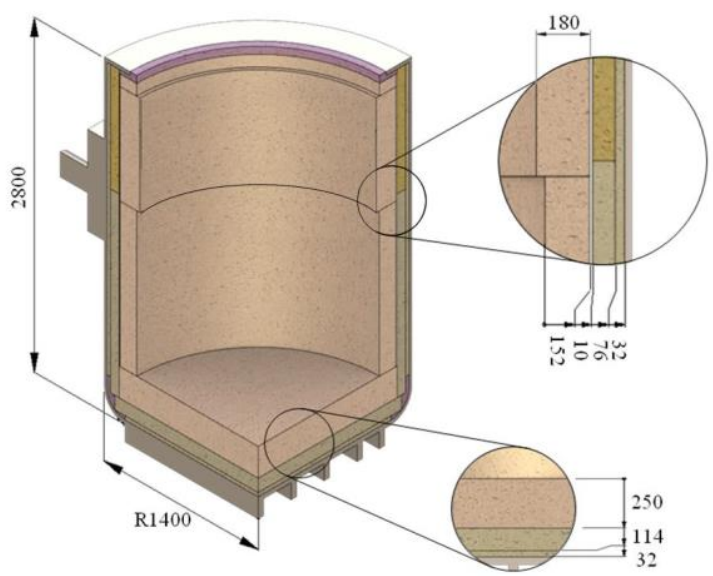

Figura 5. Modelo da Panela de aço.

Como o objetivo do trabalho é analisar as condições dos estados das juntas durante o pré-aquecimento do refratário, um carregamento transiente de temperatura foi aplicada nas faces do revestimento de trabalho em contato com o aço. A Figura 6 apresenta a curva de temperatura da face quente do refratário em função do tempo. No cálculo do perfil térmico, também foi considerado trocas térmicas devido a radiação (emissividade $\varepsilon=0,85$ ) e convecção (coeficiente convectivo variando com a temperatura), entre a panela e o ambiente.

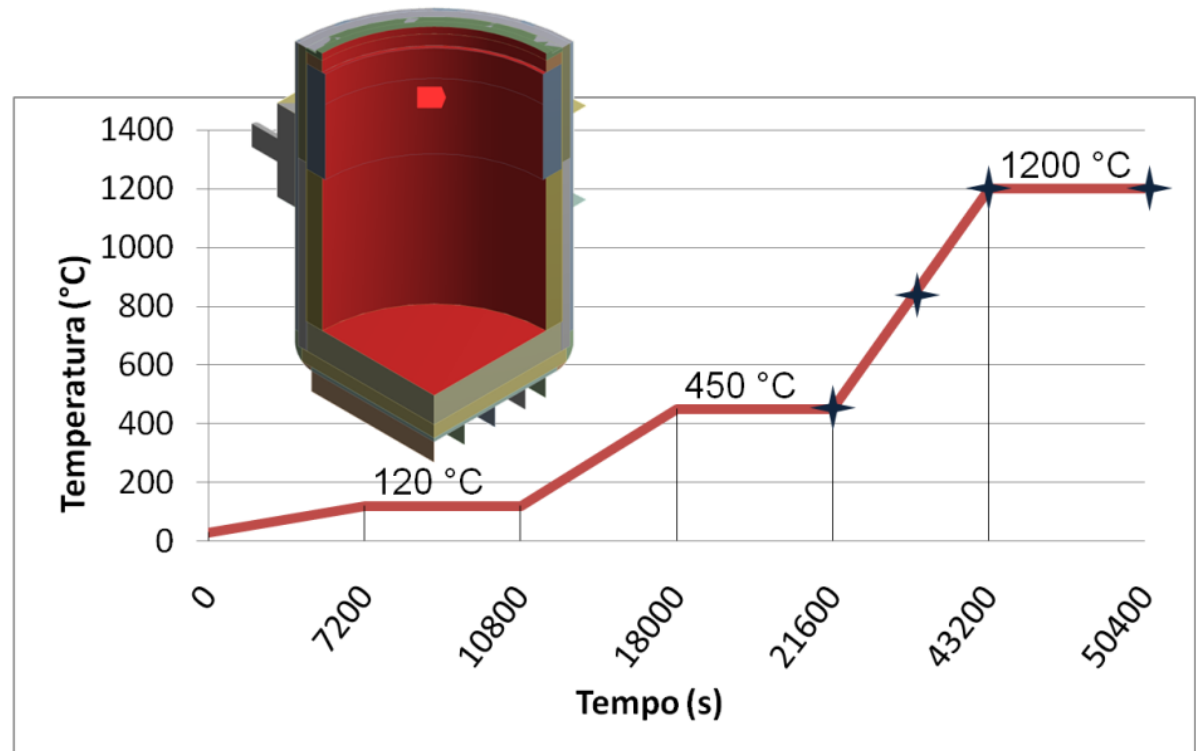

Figura 6. Curva de temperatura aplicada nas faces quentes do revestimento de trabalho. 
Os resultados de perfis de temperatura dos pontos 21600s, 32400s, 43200s e 50400 s foram usados no modelo estrutural estático, no qual a Homogeneização Periódica é implementada, a fim de calcular o perfil de tensão na Panela e no refratário, além dos estados das juntas.

Quatro diferentes configurações foram modeladas: sem junta (também chamada de isotrópica em função do comportamento mecânico do); juntas de $0,1 \mathrm{~mm}$, juntas de $0,35 \mathrm{~mm}$ e juntas de $0,5 \mathrm{~mm}$. Na aplicação nos vasos metalúrgicos, as juntas entre os refratários aparecem na forma de imperfeições, rugosidade, da superfície do tijolo. Mesmo que os tijolos estejam em contato, a presença das juntas permite alguns níveis de expansão térmica sem a geração de valores significativos de compressão.

O coeficiente de Poisson de todos os materiais refratários foi considerado igual a 0,2 . Os módulos elásticos, entretanto, variam com a temperatura de acordo com as curvas da Figura 7.

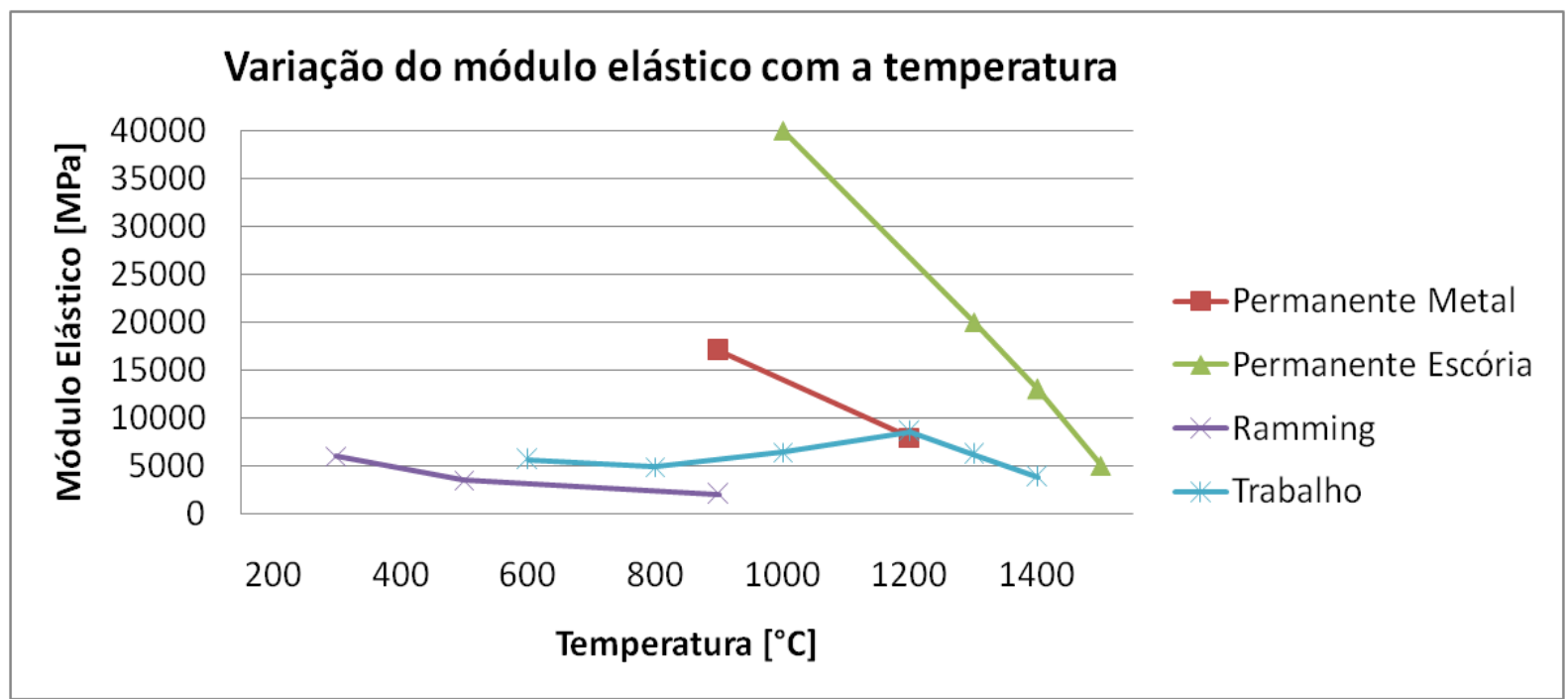

Figura 7. Variação do módulo elástico com a temperatura para cada material da Panela de aço.

Os coeficientes de expansão térmica dos materiais não homogeneizados não variam em função da temperatura e seus valores são: $1,4 \mathrm{E}-5 /{ }^{\circ} \mathrm{C} ; 6,3 \mathrm{E}-6 /{ }^{\circ} \mathrm{C}$ e $1,0 \mathrm{E}-6 /{ }^{\circ} \mathrm{C}$ para os revestimentos Permanente Escória, Permanente Metal e Ramming, respectivamente. A mesma propriedade, para o material homogeneizado, varia em função da temperatura e os valores usados na simulação estão apresentados na Tabela 2 a seguir:

Tabela 2. Coeficientes de expansão térmica do material Homogeneizado.

\begin{tabular}{lcccccc}
\hline Temperatura & $600{ }^{\circ} \mathrm{C}$ & $800{ }^{\circ} \mathrm{C}$ & $1000{ }^{\circ} \mathrm{C}$ & $1200{ }^{\circ} \mathrm{C}$ & $1300{ }^{\circ} \mathrm{C}$ & $1400{ }^{\circ} \mathrm{C}$ \\
\hline $\begin{array}{l}\text { Coeficiente de expansão } \\
\left.\text { térmica [ } /{ }^{\circ} \mathrm{C}\right]\end{array}$ & $8,5 \mathrm{E}-6$ & $7,81 \mathrm{E}-6$ & $9,08-6$ & $1,08 \mathrm{E}-5$ & $1,13 \mathrm{E}-5$ & $1,18 \mathrm{E}-5$ \\
\hline
\end{tabular}

\section{RESULTADOS E DISCUSSÃO}

O fechamento da junta acontece devido à expansão térmica do tijolo, portanto é esperado que as juntas se fechem ao decorrer do aquecimento da Panela. A Figura 8 exemplifica o fechamento das juntas através do caso com junta de $0,5 \mathrm{~mm}$ entre os tijolos. 

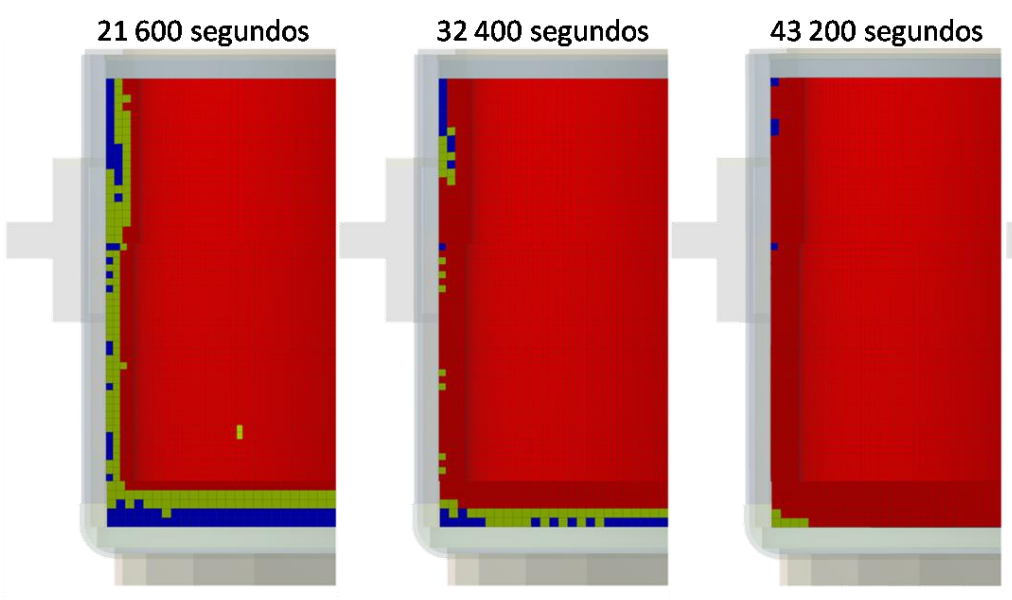

50400 segundos

Estado da
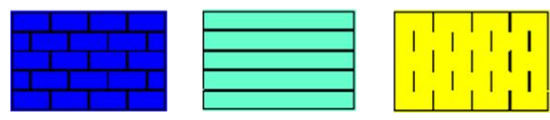

3

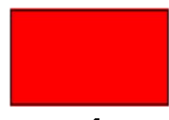

4

Figura 8. Evolução do fechamento das juntas para o caso com junta de $0,5 \mathrm{~mm}$ de espessura.

É possível notar que as juntas mais próximas à face quente já estão fechadas após 21600 segundos da curva de aquecimento da Panela, porém as regiões mais próximas às carcaças fecham somente após a temperatura da face quente ultrapassar os $450{ }^{\circ} \mathrm{C}$. Passados 32400 segundos, onde a temperatura máxima do domínio atinge $825^{\circ} \mathrm{C}$, a região de juntas no estado 4 aumenta até que a temperatura no interior da Panela atinja o patamar de $1200^{\circ} \mathrm{C}$ e praticamente toda a configuração refratária se encontra com as juntas fechadas, tanto verticalmente quanto horizontalmente.

A Figura 9 é uma comparação dos estados das juntas no fundo da Panela entre 0 instante após 32400 e 43200 segundos do início da curva de pré-aquecimento. Com o auxílio desta análise, pode-se perceber o risco de interromper o processo de préaquecimento da Panela durante a segunda rampa da curva apresentada na Figura 6.

\section{0 segundos}

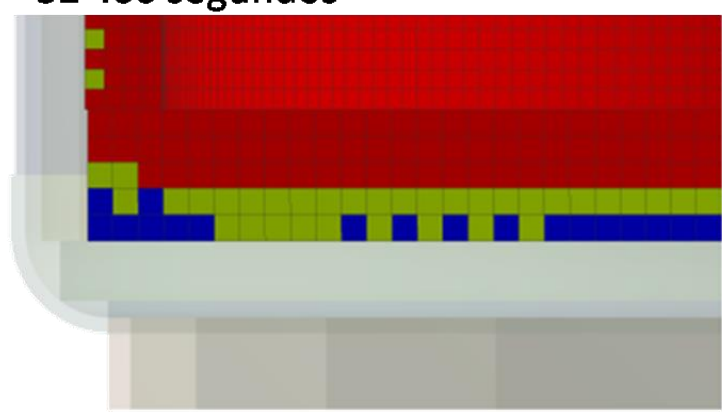

(a)

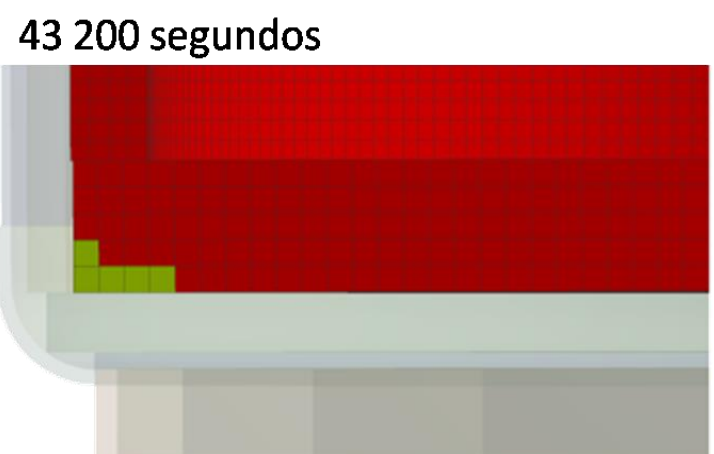

(b)

Figura 9. Comparação dos estados das juntas no instante de 32400 (a) e 43200 (b) segundos, no fundo da Panela. 
Se, por hipótese, o pré-aquecimento fosse interrompido logo após 32400 segundos, os tijolos se encontrariam em temperaturas mais frias e por isso as consequências do choque térmico durante a operação seriam maximizadas, podendo causar falhas prematuras do refratário. Além dessa análise direta, como existe uma inércia vinculada à mudança de estado das juntas, os tijolos tendem a expandir ao entrar em contato com o aço fundido, e se as juntas não estão fechadas, a área de contato inicial entre os tijolos é menor, o que causa o aumento do nível de tensões que podem corroborar para aumento de trincas, falhas por fadiga e spalling.

Além das consequências de natureza térmica estrutural, o não fechamento de juntas podem ocasionar falhas mais preocupantes no âmbito da segurança do trabalho. $O$ manuseio do aço líquido pode representar um risco caso as juntas não forem fechadas e o aço $\left(a_{1600}^{\circ} \mathrm{C}\right)$ entrar em contato com a carcaça metálica.

A figura 10 mostra a evolução do perfil de temperaturas do fundo da panela ao longo da análise térmica transiente. Como é possível observar, existem diferenças de aproximadamente $100^{\circ} \mathrm{C}$ entre as temperaturas da face fria dos dois últimos instantes de tempo, o que indica que, mesmo no patamar, há variações do perfil térmico no tempo. Dessa maneira, a análise transiente torna-se necessária, já que um cálculo permanente superestimaria valores de temperatura ao longo da espessura, podendo levar ao fechamento equivocado das juntas do modelo.

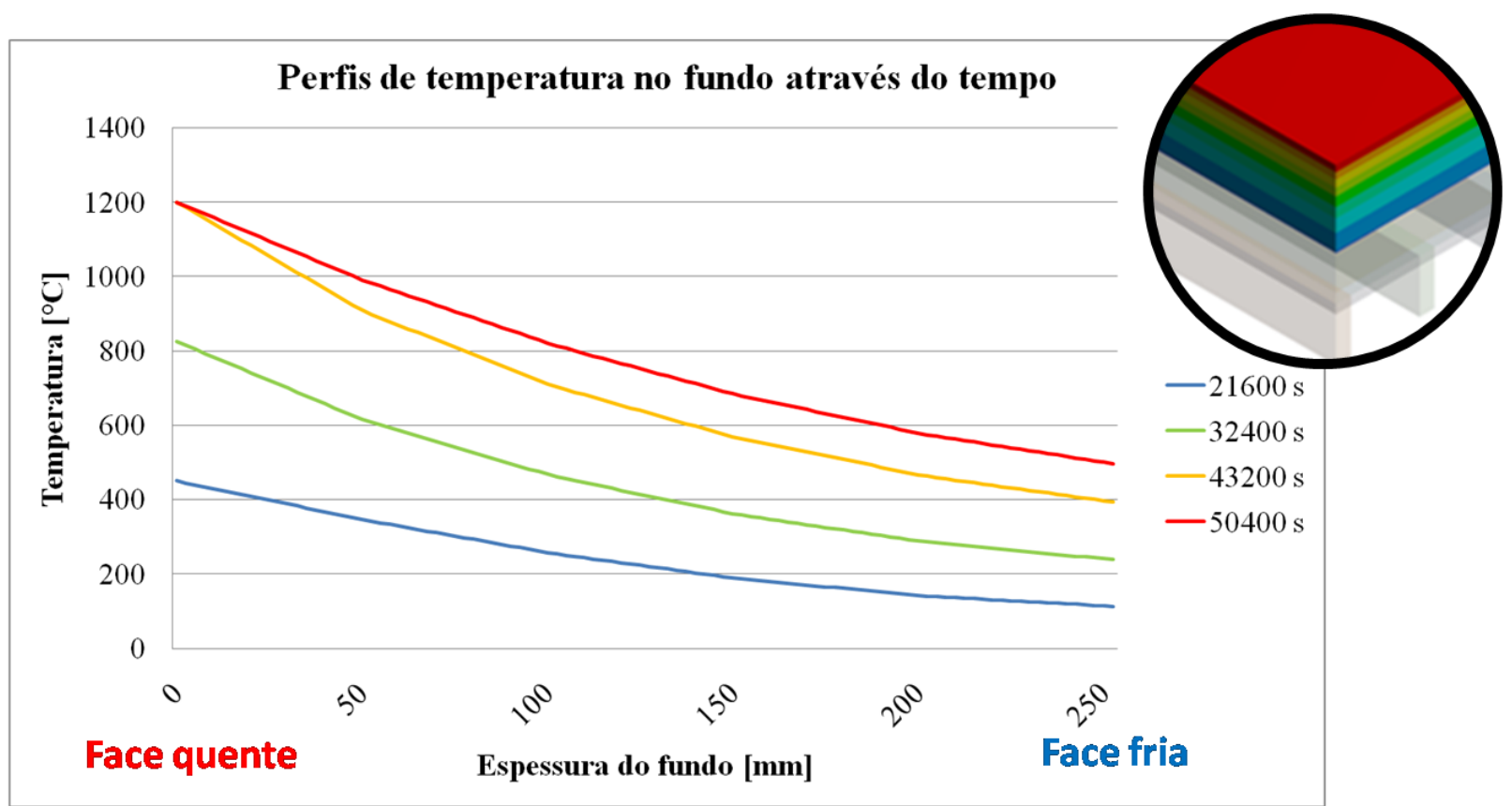

Figura 10. Valores da temperatura do refratário na espessura do fundo da configuração em diferentes instantes de tempo.

A Figura 11 apresenta os níveis de tensão normal na direção circunferencial presentes nas quatro configurações simuladas. É possível notar a influência do tamanho da junta, no nível de tensão do refratário. Além disso, percebe-se que no caso isotrópico, os valores de tensão máxima e sua área de influência são superestimados, o que compromete o sucesso da análise. 


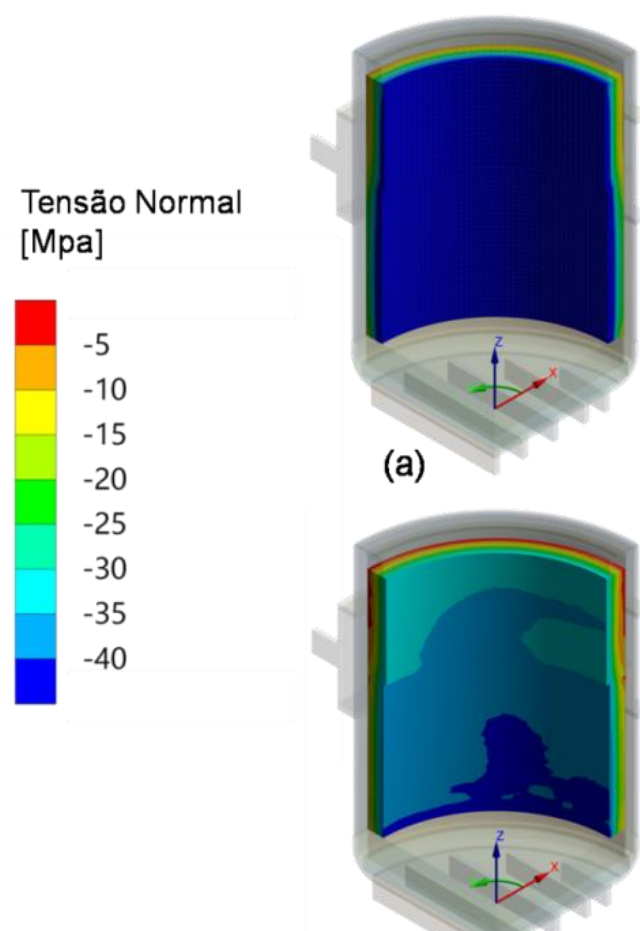

(c)

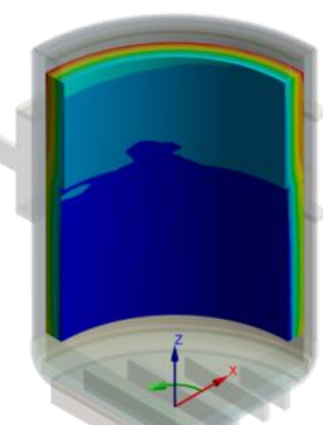

(b)

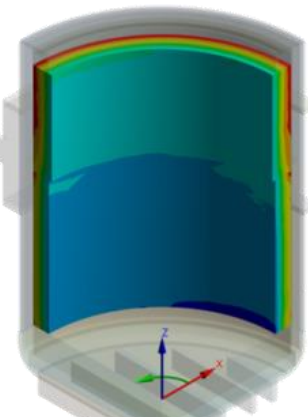

(d)

Figura 11. Tensão normal, na parede da Panela, na direção circunferencial nas configurações: sem junta (a); junta de $0,1 \mathrm{~mm}$ (b); junta de $0,35 \mathrm{~mm}$ (c) e junta de $0,5 \mathrm{~mm}$ (d).

Nota-se que as áreas onde os valores de compressão excedem o valor de $40 \mathrm{MPa}$ é menor nas configuração com juntas maiores. Quanto maior o tamanho da junta, maior é a expansão térmica que não resulta em aumento de tensão, pois o tijolo pode expandir livremente até que encontre a superfície do tijolo vizinho. Por conseguinte, é de se esperar que o modelo isotrópico, sem levar a existência de juntas em consideração, apresente valores absolutos de tensão maiores que 0 modelo de Homogeneização Periódica. A Figura 12 apresenta a mesma análise porém no fundo da Panela de aço.

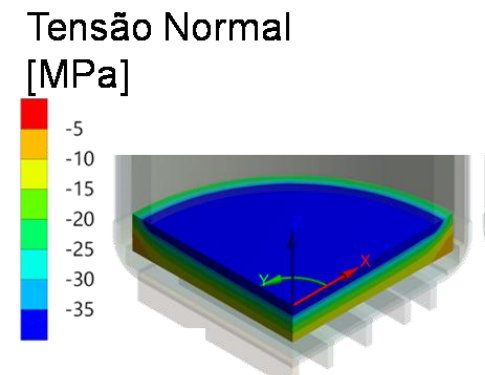

(a)

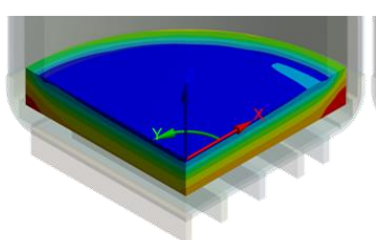

(b)

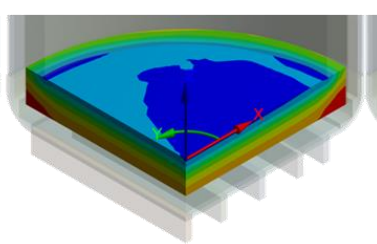

(c)

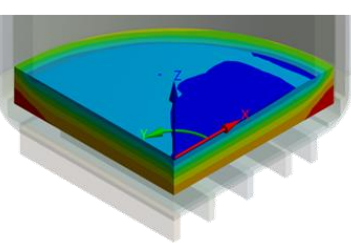

(d)

Figura 12. Tensão normal, no fundo da Panela, na direção circunferencial nas configurações: sem junta (a); junta de $0,1 \mathrm{~mm}$ (b); junta de $0,35 \mathrm{~mm}$ (c) e junta de $0,5 \mathrm{~mm}$ (d).

A análise acima se estende às tensões presentes na carcaça da Panela de aço. A Figura 13 apresenta a tensão equivalente de von Mises ao longo de uma linha vertical na carcaça, nela é possível perceber a diferença de tensões tanto entre as configurações de juntas diferentes quanto entre os modelos isotrópico e HPL. 


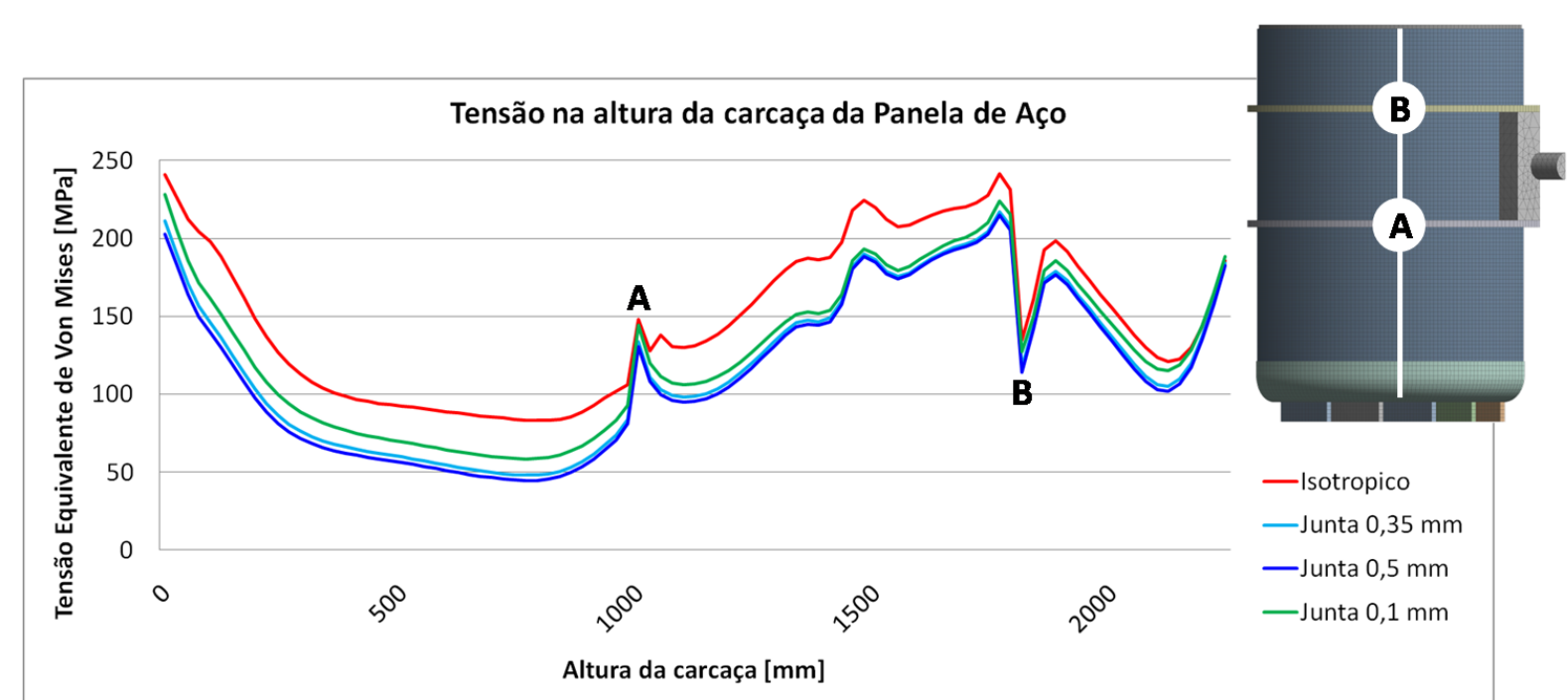

Figura 13. Tensão equivalente de von Mises ao longo de uma linha vertical na carcaça da Panela de aço para os diferentes modelos e configurações.

A diferença das tensões equivalente de Von Mises entre o modelo isotrópico e o modelo HPL pode chegar a quase $50 \mathrm{MPa}, 20 \%$ do valor máximo presente na carcaça. Esse erro, inerente ao modelo isotrópico, pode gerar má interpretação das condições do processo e, consequentemente, tomadas de decisão incorretas. É possível, também, observar que os valores das tensões são iguais para todas as configurações nos pontos $\mathrm{A}$ e $\mathrm{B}$, devido aos anéis de reforço presentes nessas alturas.

Dentre as simulações, com a presença de juntas secas, pode-se perceber um padrão em que quanto maior a junta, menores são os valores de tensão na carcaça da Panela e no refratário. Contudo, sabe-se que quanto maior a espessura da juntas, maior deve ser a carga térmica imposta ao sistema para que ela se fechem, aumentando a probabilidade de não fechamento dessas juntas.

\section{CONCLUSÃO}

O comportamento ortotrópico, dependente da temperatura, de um material homogêneo equivalente à configuração refratária sem argamassa foi determinado usando o método de Homogeneização Periódica Linear. O critério de fechamento do modelo permite o cálculo do estado das juntas. O material equivalente foi usado para simular uma Panela de aço durante o processo de pré-aquecimento através das análises térmica-transiente e estática-estrutural.

O modelo nos permite prever quais juntas vão fechar e quais permanecerão abertas após a aplicação de cargas térmicas impostas na simulação. É possível observar que o tamanho das juntas está diretamente relacionado com o nível de tensões presente na carcaça metálica e no refratário. Juntas maiores tem efeitos benéficos no perfil de tensões porém dificultam o fechamento das mesmas durante o aquecimento do sistema. Assim sendo, cabe ao projetista decidir o tamanho da junta que diminuirá as chances de falhas termo-mecânicas do refratário sem afetar as condições seguras de operação.

Apesar da ferramenta apresentar recursos de grande utilidade, existe algumas restrições no seu uso devido à dificuldade de obtenção das propriedades termomecânicas do material refratário. A entrada de dados de propriedades muito 
divergentes da realidade pode ocasionar em resultados duvidosos e, por conseguinte, ações equivocadas.

O modelo será aperfeiçoado levando em consideração o comportamento não linear do refratário usando a técnica de Homogeneização Periódica Não-Linear.

\section{Agradecimentos}

Os autores gostariam de agradecer à Magnesita Refratários e à FIRE (Federation for International Refractory Research and Education) pelo apoio neste trabalho.

\section{REFERÊNCIAS}

1 A. Rafiee, M. Vinches, C. Bohatier: Modelling and analysis of the Nîmes arena and the Arles aqueduct subjected to a seismic loading, using the Non-Smooth Contact Dynamics method, Engineering Structures, 30(2008)[12] 3457-3467

2 A. Cecchi, K. Sab: A multi-parameter homogenization study for modeling elastic masonry, Eur. J. of Mech. - A / Solids, 21(2002) [2] 249-268

3 A. Cecchi, K. Sab: Out of plan model for heterogeneous periodic materials: the case of masonry,Eur. J. of Mech. - A / Solids, 21(2002) [5] 715-746

4 A. Anthoine: Derivation of the in-plane elastic characteristics of masonry through homogenization theory, Int. J. Solid Structures, 32(1995)[2] 137-163

5 R. Luciano, E. Sacco: Homogenization technique and damage model for old masonry material, Int. J. of Solids and Structures,34(1997) [24]3191-3208

6 T.M.H. Nguyen, E. Blond, A. Gasser, T. Prietl: Mechanical homogenisation of masonry without mortar, Eur. J. of Mech. A, 28(2009)[3] 535-544

7 J. Brulin, F. Roulet, A. Rekik, E. Blond, A. Gasser, R. McNally, M. Micollier: Latest Evolution in Blast Furnace Hearth thermo-Mechanical Stress Modelling, Proc. 4th STEEL SIM, Düsseldorf (2011) 